\section{Des conditions de travail humaines pour les médecins-assistants}

Prise de position de la FMH concernant l'initiative parlementaire Suter

Madame la Conseillère aux Etats, Monsieur le Conseiller aux Etats,

En prévision du prochain débat sur l'initiative parlementaire Suter intitulée "Des conditions de travail humaines pour les médecins-assistants", nous nous permettons ici de vous informer que la Fédération des médecins suisses (FMH), représentée par son Comité central, apporte à cette initiative son entier soutien. Ce soutien vaut également en regard des quelques voix critiques parmi nos membres, que nous respectons et dont nous vous prions de tenir compte dans l'approche de cette initiative.

Nous motivons notre soutien comme suit:

1. Diverses études, dont celle menée dans le canton de Berne, montrent que les médecins-assistants travaillent 70 heures par semaine et même davantage. Dans les disciplines chirurgicales et interventionnelles, cette moyenne est encore plus élevée. Un élément aggravant consiste dans le fait qu'une partie de ce travail doit être accompli en dehors des heures habituelles, le soir, la nuit ou le week-end ... avec les conséquences physiques et psychosociales que l'on peut imaginer. Cette si- tuation est inacceptable, surtout si l'on considère que les médecins-assistants - il ne s'agit pas d'apprentis, mais d'universitaires - portent de lourdes responsabilités.

2. Ceux qui profitent de ce système sont l'Etat et les assureurs, qui créent ou se procurent ainsi, implicitement, des prestations meilleur marché. A une époque où la transparence des coûts est devenue à bon droit une règle de conduite, ces subventions croisées à la charge du tiers le plus faible n'ont définitivement plus leur place. Seule la transparence des coûts peut montrer dans quelle mesure le précieux temps de travail d'universitaires est mal utilisé dans une gestion obsolète, inefficace, nullement adaptée aux exigences médicales.

3. L'argument selon lequel une grande partie du temps de travail serait consacré à l'étude et à la formation postgraduée de spécialiste est largement sans objet. Seul un petit nombre de divisions hospitalières connaissent des curricula de formation postgraduée structurés; dans la plupart des divisions, la formation structurée incluant un enseignement efficace au chevet du patient est de moins de 5 heures par semaine, pour autant qu'elle existe.

4. L'assujettissement à la Loi sur le travail ne doit pas conduire à une surréglementation rigide. Les volontaires qui, pour des raisons personnelles, veulent consentir un effort particulier, doivent pouvoir continuer de le faire. Un effort particulier ne signifie pas toutefois qu'il devienne la règle.

Veuillez agréer, Madame la Conseillère aux Etats, Monsieur le Conseiller aux Etats, l'expression de mes sentiments les meilleurs.

Dr H. H. Brunner, Président de la FMH 